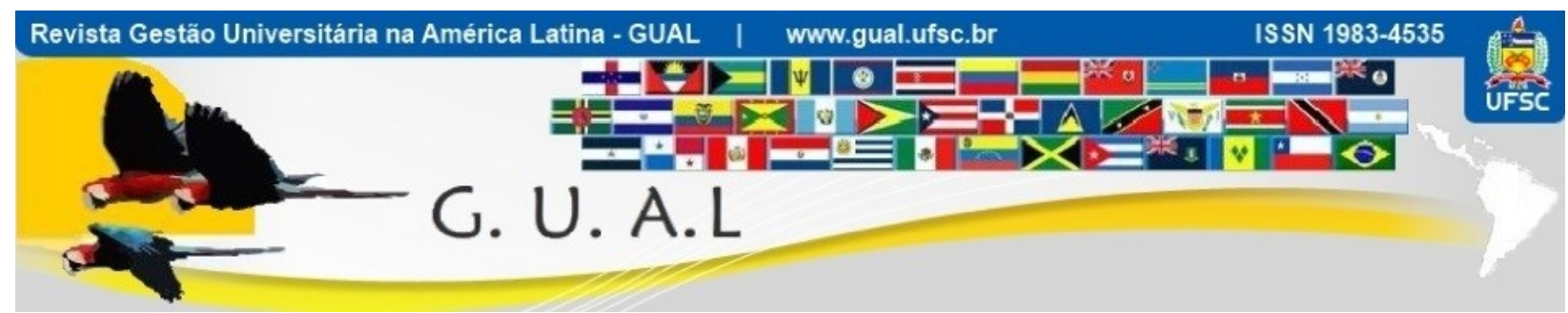

DOI: http://dx.doi.org/10.5007/1983-4535.2018v11n4p147

\title{
PROCESSO ADMISSIONAL E LOTAÇÃO DE PESSOAL: A REALIDADE DE UMA IFES
}

\author{
ADMISSION PROCESS AND STAFF PLACEMENT: AN IFES' REALITY
}

Susan Mary Vieira de Almeida, Mestre Universidade Federal da Bahia - UFBA ssusanvieira@gmail.com

Denise Ribeiro de Almeida, Doutora Universidade Federal da Bahia - UFBA deniserib@gmail.com

Antônio Raimundo Cardoso Teixeira Filho, Mestre Universidade Federal da Bahia - UFBA antonior79@gmail.com

Leonardo Ribeiro de Almeida, Graduado Universidade Federal do Estado do Rio de Janeiro - UNIRIO leoribal@gmail.com

Recebido em 24/novembro/2017

Aprovado em 06/setembro/2018

Sistema de Avaliação: Double Blind Review

Esta obra está sob uma Licença Creative Commons Atribuição-Uso. 


\title{
RESUMO
}

$\mathrm{O}$ artigo analisa a efetividade do instrumento utilizado quando da entrevista admissional e sua relação com a lotação dos servidores ocupantes do cargo de Assistente em Administração, admitidos no concurso público realizado em 2013, na UFBA. Para o cumprimento do objetivo da pesquisa, aplicou-se via Survey,um questionário, com base na escala Likert, composto por cinco categorias. Também se realizou pesquisa documental e observação ativa. Os resultados apontaram que, em geral, há certo grau de satisfação em todas as dimensões avaliadas, entretanto um número significativo de servidores não considerou que a definição de sua unidade de lotação levou em conta suas competências profissionais, apesar de alguns afirmarem que estas foram adequadamente identificadas, reforçando a visão de que a entrevista admissional tem sido realizada de forma efetiva, mas seus resultados não são aproveitados no processo de lotação. Aponta-se como principal limitação dessa pesquisa o escopo da população estudada, assim, sugerem-se novas pesquisas com envolvimento da alta gestão (pró-reitores, coordenadores/chefes de equipes de trabalho e dirigentes de unidades administrativas e acadêmicas), bem como o aprimoramento dos instrumentos utilizados no processo admissional da UFBA.

Palavras-chave: Gestão de Pessoas no Serviço Público. Processo Admissional e de Lotação de Pessoal. IFES.

\begin{abstract}
This article analyzes the effectiveness of the used instrument in the moment of the admission interview and its relation with the placement of the servers that occupy the position of Management Assistants, admitted in UFBA's 2013 public competition. For the fulfillment of the research's objective, it was applied, by Survey, a questionnaire, based on the Likert scale, composed of five categories. It was also fulfilled documental research and active observation. The results had pointed that, in general, there is a certain degree of satisfaction in all the evaluated dimensions, however a significant number of servers did not consider that the definition of its placement took notice of its professional abilities, although some affirmed that those were correctly identified, strengthening the vision that the admission interview has been carried effectively, but its results are not exploited in the placement process. It is pointed, as the main limitation of this research, the range of the studied population, thus, it is suggested to conduct new researches with the involvement of the high sectors of management (pro-rectors, coordinators/leaders of work teams and heads of administrative and academic units), as well as the improvement of the instruments used in UFBA's admission process.
\end{abstract}

Keywords: Personnel Management in the Public Service. Admission Process and Staff Placement. IFES 


\section{INTRODUÇÃO}

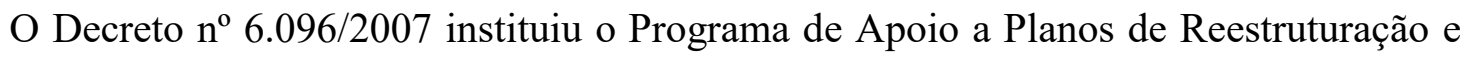
Expansão das Universidades Federais (REUNI), o qual, segundo Almeida (2011 e 2012) tem como objetivo principal criar condições para a ampliação do acesso e permanência na educação superior, para melhor aproveitamento da estrutura física e de recursos humanos existentes nas universidades federais.

Além deste decreto, outros dois são publicados em sequência com o objetivo de sistematizar de maneira mais consistente alguns dos seus aspectos relativos à concessão de fornecer maior autonomia às Instituições Federais de Ensino Superior (IFES) no que ser refere à recomposição dos seus quadros docentes e técnicos sem a necessidade de autorização do governo federal - o 7.232/2010 e o 7.485/2011. Assim, os cargos contemplados pelos concursos públicos para servidores técnico-administrativos começaram a ser realizados de forma rotineira, incluindo neste leque o cargo de Assistente em Administração (TAE), o mais demandado por estas organizações, por conta da sua natureza administrativa.

Nesse cenário, as IFES, que ao longo dos últimos anos conviviam com um cenário de quadros de servidores praticamente estagnado, começaram a repor seu déficit de pessoal, inclusive contemplando-se as necessidades de aumento advindas do processo de ampliação decorrente do REUNI. Entretanto, como apontam Brandão e Guimarães (2001), Bergue (2010). Brandão (2013) e Teixeira Filho e Almeida (2014), a falta de uma política de planejamento para adequar a qualificação desses recém-ingressos às rotinas de trabalho que os aguardavam, deve ser suprida com a adoção de um modelo de gestão estratégica de pessoas, baseado em competências.

Sob tal contexto, entende-se ser importante o estudo deste fenômeno em IFES com diferentes peculiaridades, desde aquelas mais antigas e criadas sob um paradigma tradicional, quanto naquelas que surgem a partir do REUNI. Neste sentido, entende-se que estudar o processo ocupacional e a alocação dos TAE na UFBA é relevante, por conta da representatividade desta organização no cenário nacional, em diferentes momentos da oferta do ensino superior. Como justificativa a tal concepção, os autores deste artigo baseiam-se nas concepções apresentadas por Teixeira Filho e Almeida (2014) e Almeida (2011 e 2012) sobre o papel da UFBA no surgimento de das universidades federais, no final dos anos de 1950; do processo de Reforma Universitária, ao término da década de 1960 e, na sistematização do que viria ser o REUNI. 
A fim de mais bem se caracterizar a UFBA, destaca-se que hoje, segundo Quadro de Referência dos Servidores Técnico-Administrativo em Educação (QRSTAE), disponível no sítio eletrônico da Instituição, a mesma possui 2.850 servidores técnico-administrativos, sendo que deste total, 772 ocupam o cargo de Assistente em Administração. Além disso, a partir da observação de um dos autores do artigo, acerca dos processos de remoção que tramitam na Coordenação de Desenvolvimento Humano (CDH) da UFBA, sabe-se que muitos desses técnicos estão bem adaptados às suas atividades rotineiras, desempenhando-as com eficiência e satisfação, entretanto, alguns servidores estão insatisfeitos com as atividades demandadas por suas chefias imediatas ou, até mesmo, com a natureza do ofício. Por sua vez, essa inadequação provocada pela presença de perfis incompatíveis com o ambiente de lotação, produz resultados negativos, tais como, servidores e dirigentes insatisfeitos, dificuldade de relacionamento interpessoal, adoecimento, rotatividade, resultando em baixa qualidade do serviço prestado.

Assim com base nesta problematização inicial, este artigo traz como questão de pesquisa: Quais as contribuições da entrevista admissional na UFBA ao processo de lotação dos TAE recém contratados? Destaca-se que neste texto, os termos lotação, alocação e locação de pessoal são usados como sinônimos. Com o intuito de responder a esta questão aplicou-se uma pesquisa junto aos TAE, ingressos em 2013. O artigo tem como objetivo geral: analisar a efetividade da entrevista admissional realizada na UFBA e a posterior alocação dos servidores recém-contratados, desdobrando-se nos objetivos específicos: a) verificar como a entrevista admissional é realizada; b) avaliar se o processo de alocação foi feito de forma adequada com base na visão dos TAE; c) identificar a relação da entrevista admissional com o processo de lotação dos TAE.

Este artigo, além desta introdução que busca apresentar sua problematização, traz o referencial teórico que o ancora, tomando por base discussões relativas à evolução da gestão de pessoas no serviço público a partir das modificações implementadas no Estado brasileiro com o Plano Diretor da Reforma do Estado (PDRAE). Sua terceira seção apresenta os procedimentos metodológicos utilizados na elaboração do estudo, que tem seus resultados discutidos na seção seguinte. O trabalho se encerra, com algumas considerações finais, suas limitações e sugestões de possíveis estudos futuros. 


\section{GESTÃo ESTRATÉGICA DE PESSOAS NO SERVIÇO PÚBLICO}

Segundo Bresser-Pereira (1996), Brasil (1998) e Abrúcio (2007), o Estado e o mercado são instituições fundamentais para a manutenção do equilíbrio do sistema capitalista contemporâneo. Geralmente uma crise é fruto do desequilíbrio entre esses dois entes, como o que ocorreu no Brasil na década de 1920 a 1930, caracterizado pela crise do mercado e nos anos 70 a 80 , período em que o país ficou marcado pelo alto índice inflacionário, desemprego e diminuição nas taxas de crescimento econômico. Essa crise levou o governo a pensar a reconstrução do Estado nos anos 90. Paralelamente, esse contexto estava presente em toda a América Latina, sendo necessária a adoção de um pacote de reformas, de modo a promover o desenvolvimento desses países, com vistas a recuperar suas economias. Esse processo destacou o papel do mercado, proporcionando a abertura do comércio internacional.

Ainda conforme os autores anteriores, surge no Brasil, como demanda a reforma do Estado, e na segunda metade dos anos de 1980, a necessidade de se redefinir a sua atuação, em virtude da forte crise fiscal. Esse período foi marcado por uma alta inflação, desemprego e dívida externa. A reforma do Estado significava redimensionar sua estrutura e seu corpo funcional buscando implementar a administração pública gerencial, ou seja, uma administração descentralizada, com foco no resultado, mais eficiente e mais ágil.

Nesse contexto de crise, tanto no setor público, como no privado, o processo de globalização da economia alterou de forma significativa o cenário mundial, provocando mudanças, e consequentemente, elevando a competitividade do mercado interno que precisou traçar estratégias para diferenciar-se e tornar-se mais produtivo nesse ambiente. No Brasil esse processo foi intensificado a partir dos anos de 1990. Para Pereira (1996), esse momento foi marcado pela grande crise do Estado brasileiro, gerado pela perda do poder aquisitivo e dos altos índices inflacionários. Ainda segundo este autor, este momento de crise foi crucial para a redefinição das funções do Estado, que anteriormente tinha como meta a proteção de sua economia da concorrência internacional; posteriormente, entretanto, sua meta era tornar a economia nacional internacionalmente competitiva. Sob tal contexto, as instituições governamentais viram-se pressionadas a se preparar para esse momento de mudanças, repensando suas estratégias para assim garantir o alcance de seus objetivos.

Ainda sob tal contexto, os usuários do serviço público tornam-se cada vez mais conscientes de seus direitos, sendo assim mais exigentes quanto ao atendimento de suas demandas. Sob tal aspecto, Schikmann (2010) pontua que a sociedade espera das 
organizações públicas a prática de ações com foco em resultados, ou seja, que essas organizações prezem pela eficiência, bem como pela eficácia e efetividade nas ações governamentais.

Com tal foco, a Emenda Constitucional no $19 / 98$ apresenta um importante avanço ao introduzir o princípio da Eficiência. Esse princípio relaciona-se diretamente ao conceito de eficácia e de qualidade dos serviços, refletindo-se em uma administração que investe na capacitação de seus servidores, na redução de gastos, na otimização de recursos, "vinculados a um projeto mais amplo e integrado de modernização da Administração Pública" (ABRÚCIO, 2007, p.81)

Especificamente no que diz respeito à gestão de pessoas, Bergue (2010, p.45) afirma que pensar a gestão estratégica é "pensar a organização como um todo, em todas as suas instâncias, relacionada ao seu contexto e orientada para o longo prazo". Complementando tal concepção, Domingues (2006) considera que as sociedades contemporâneas têm sofrido o impacto de profundas mudanças ocasionadas pela forma como a sociedade se organiza hoje. Muitas são as identidades sociais e individuais construídas ao longo desse processo, fazendo com que as instituições se transformem para o atendimento desse novo grupo de pessoas.

Sendo assim, a partir dos trabalhos de Bergue (2010) e Schikmann (2010), infere-se que as IFES, enquanto organizações públicas, têm a responsabilidade não só de expandir o ensino superior, como também de proporcionar um ensino público, gratuito e de qualidade. É nesse sentido que essas instituições buscam se ajustar para encontrar novas formas de gestão que possibilitem o cumprimento de sua função social de forma plena e que as preparem para esse período de transformações sociais, políticas e econômicas, somadas a um público mais qualificado, mais exigente e com novas necessidades a serem supridas.

Diante desta necessidade de se buscar soluções para o cumprimento de sua função social, com transparência, agilidade e eficiência, as IFES precisam reavaliar as suas estruturas atuais, buscando distanciar-se cada vez mais dos modelos clássicos de gestão com vistas à efetivamente adotarem uma postura inovadora na forma de lidar com o cidadão como usuário final do serviço público que prestam.

Sob tal prisma, Schikmann (2010) leciona que a gestão estratégica deve estar alinhada aos objetivos e metas da organização e com os meios mais adequados para alcançá-los, tendo em vista o curto, médio e longo prazos. Deve-se planejar e monitorar suas ações, capacitar seus profissionais em seus diversos níveis para o bom desempenho de suas ações. Alday (2000) adicionalmente afirma que essas ações conduzem a um gerenciamento voltado a 
aspectos importantes ou relevantes, fazendo com que a organização deve ter bem definida sua missão, visão e valores para assim trabalhar de forma estratégica e atingir seus objetivos.

Neste cenário de mudanças do Estado e de adoção de práticas antes comuns da iniciativa privada, dentre elas gestão estratégica de pessoas, o governo federal publica o Decreto $\mathrm{n}^{\mathrm{o}} 5.707 / 2006$, que instituiu a Política Nacional de Desenvolvimento de Pessoal (PNDP) que tem como um de seus instrumentos a implementação do sistema de gestão por competência, definida como gestão da capacitação orientada para o desenvolvimento do conjunto de conhecimentos, habilidades e atitudes necessárias ao desempenho das funções dos servidores, visando ao alcance dos objetivos da organização.

Para Zarifian (2001), Brandão e Guimarães (2001) e Brandão (2013), a competência pode ser vista como a forma pela qual o indivíduo reage frente às situações que ocorrem em seu ambiente de trabalho. Ou seja, o indivíduo deve estar consciente e mobilizado para assumir o seu papel de ator ativo no contexto organizacional em que atua. Desta forma, quando se verifica esta situação, os objetivos organizacionais são mais facilmente alcançados, tendo-se assim maior reconhecimento pessoal, e a geração de valor econômico e social para a organização e para o funcionário. Fica clara assim, a importância da utilização do conceito da estratégica de pessoas com ou uso do modelo de competências na alocação de pessoas nas organizações públicas em geral, e nas IFES no particular.

Buscando trazer um foco mais operacional a este processo, Schikmann (2010) afirma que a área de gestão de pessoas é a responsável por conhecer a organização e cada uma de suas áreas, a fim de prover a alocação mais adequada dos seus recursos humanos. Explicitando mais esta concepção Brandão e Guimarães (2001) e Bergue (2010) lecionam que a estratégia aponta para o futuro desejado pela organização, suas diretrizes e formulação política para a obtenção e desenvolvimento de competências para atingir seus objetivos. Com isso, o desafio da área de gestão de pessoas passa pela necessidade de se mapear competências, identificando-se o conjunto dos conhecimentos, habilidades e atitudes dos seus funcionários, para a partir daí, alinhá-los às estratégias, ou seja, a missão, visão e objetivos da organização.

Para facilitar a implementação deste processo, é fundamental que sejam analisados à luz do contexto prático vivenciado pela organização, os aspectos apontados em Bess (2016) na operacionalização de um modelo de alocação dos TAE em uma IFES. Nesta proposta, a autora parte da descrição clara e direta das tarefas a serem executadas em diferentes contextos da IFES pesquisada, passando pelo mapeamento das competências individuais existentes, para 
a partir deste mapeamento fazer a alocação dos servidores buscando a maior aderência possível a estes achados.

Avançando em tal concepção, entende-se não se pode pensar que as competências individuais sejam suficientes para atender atividades organizacionais específicas, pois, como afirma Zarifian (2001), é de fundamental importância o conceito de competência relacionado à equipe de trabalho, sendo igualmente fundamental o papel da organização no sentido de promover a adequação das competências individuais às competências coletivas, a fim de garantir que a competência coletiva seja superior à soma das competências individuais, resultando de um salutar processo sinergético de interações sociais desenvolvidas no grupo. Na sequência, apresenta-se o percurso metodológico percorrido na elaboração do estudo que originou este artigo.

\section{METODOLOGIA}

Este trabalho, conforme Gil (1989), caracteriza-se como uma pesquisa descritiva, do tipo exploratória, pois tem como objetivo a obtenção de mais informações sobre a eficácia do processo admissional e sua relação com a definição da lotação dos servidores TAE ingressos em 2013. A pesquisa de campo foi feita sobre a forma de questionário, via ferramenta Survey Monkey, no período de 02/03 a 05/04/2017, junto aos servidores ocupantes do cargo de assistentes em administração, admitidos no concurso público, objeto do Edital 03/2013, com a finalidade de conhecer a percepção de cada um acerca do momento da entrevista admissional e sua relação com a definição da unidade de lotação.

Além disso, para atender os objetivos deste trabalho, fez-se uma pesquisa documental no Núcleo de Seleção (NUSEL) da Coordenação de Desenvolvimento Humano (CDH) da Pró-Reitoria de Desenvolvimento de Pessoas (PRODEP) da UFBA. Nesta fase tomaram-se por base documentos institucionais (Editais de concursos dos anos de 2012 a 2016), roteiros utilizados nas entrevistas admissionais, levantamento de dados do perfil dos inscritos no concurso para TAE, no SISCON (Sistema de Concursos da UFBA), realizado em 2013.

Outra técnica utilizada na coleta de dados foi a observação ativa que segundo Gil (2008), refere-se à participação do pesquisador no cotidiano do grupo pesquisado. A escolha dessa técnica deu-se em função da conveniência e oportunidade, tendo em vista que um dos autores do artigo trabalha na PRODEP, tendo fácil acesso às pessoas e documentos.

O Edital 03/2013, no qual os candidatos pesquisados ingressaram na UFBA, ofereceu 50 vagas para o cargo de Assistente em Administração, Campus de Salvador e 2 vagas para o 
Campus de Vitória da Conquista. Foram aprovados e homologados 115 candidatos. Destes, tomaram posse no cargo e entraram em exercício 96. De acordo com informação do Sistema Integrado de Pessoal da UFBA (SIP), até a data de aplicação do citado questionário, 15 servidores haviam pedido vacância, totalizando 81 servidores. Destes, responderam ao questionário 78 , correspondendo a $96,30 \%$ de respostas. Destaca-se que a vacância ocorre quando o cargo do servidor é considerado vago por motivo de exoneração, demissão, promoção, readaptação, aposentadoria, falecimento ou posse em outro cargo não cumulativo, conforme art. 33 da Lei ${ }^{\circ} 8.112$ (Brasil, 1990). No caso do concurso citado, a maioria das vacâncias ocorreu por pedido de exoneração.

Como proposto por Vergara (2009), o questionário foi preparado utilizando a escala Likert, contendo 26 perguntas fechadas, avaliadas de 1 a 5 , onde 1 correspondia a pior nota e 5 à melhor. Teve-se também uma última questão aberta, para que o respondente pudesse explora algo que achasse necessário ou importante em relação ao conteúdo pesquisado.

Para melhor identificar-se a percepção dos servidores, as perguntas foram elaboradas e organizadas em 5 dimensões, com base no referencial teórico utilizados por Baptista (2011) e adaptadas para o propósito dessa pesquisa. Foram elas, 1. Processo de lotação; 2. Relacionamento com a chefia imediata e colegas; 3 . Desempenho de atividades; 4 . Processo de Trabalho; 5. Necessidades de Capacitação. Cada uma delas estabelecia indicadores com vistas a medir o grau de concordância entre os servidores, a respeito das categorias citadas, gerando subsídios para o desenvolvimento da pesquisa.

Uma informação importante, é que um dos autores do artigo é servidor da CDH/PRODEP, órgão responsável pela seleção e recrutamento, podendo este fato provocar nos respondentes uma tendência a avaliar o processo admissional de forma mais positiva do que é efetivamente a situação real. Os resultados da pesquisa de campo são trazidos sob a forma de quadros, comentados pelos autores à luz do referencial usado.

\section{ANÁLISE E DISCUSSÃO DOS DADOS}

Esta seção do artigo divide-se em uma breve contextualização do processo de alocação de pessoas na UFBA, sendo seguida por análises de algumas das dimensões da operacionalização deste processo. 


\subsection{CONTEXTUALIZAÇÃO DA ALOCAÇÃO DE PESSOAS NA UFBA}

A UFBA é uma instituição de grande porte, com inúmeras Unidades Universitárias, subdivididas em diretorias, departamentos, colegiados, secretarias e Órgãos administrativos diversos, tais como, Pró-Reitorias, Bibliotecas, Hospitais, Museus, etc. Em todos esses ambientes o ocupante do cargo de assistente em administração pode ser lotado. Constata-se, com base nos últimos concursos realizados que, cada vez mais, os candidatos que ingressam na UFBA, apresentam qualificações muito acima daquelas exigidas para o cargo, como graduação, mestrado e, alguns até doutorado. Entende-se ser fundamental a apresentação da sistemática de alocação dos TAE na UFBA, aspectos estes a seguir explorados.

O processo de admissão na UFBA, conforme análise dos editais de concursos realizados a partir de 2012, compreende as seguintes etapas: provas escritas, provas práticas para cargos previamente estabelecidos em edital, inspeção médica de caráter eliminatório e etapa de entrevista admissional para levantamento dos perfis dos novos servidores. Os dados coletados nesta última etapa do processo são utilizados para posterior cruzamento com os perfis demandados pelos dirigentes das Unidades Universitárias, coletados através de formulário específico, com vistas a uma melhor definição da lotação dos candidatos aprovados.

A entrevista admissional é realizada por uma equipe do Núcleo de Acompanhamento da Vida Funcional, da Pró-Reitoria de Desenvolvimento de Pessoas - NAVIF/PRODEP composto por uma psicóloga, uma assistente social, um assistente em administração, com formação em psicologia e um auxiliar em administração. Esse procedimento, quando realizado pelo NAVIF, ocorre nos casos em que mais de um candidato é convocado, sendo necessário definir uma unidade de lotação para esses servidores.

Nos casos em que se tem apenas uma Unidade demandando reposição de servidor, ou seja, quando apenas um candidato é convocado para tomar posse no cargo daquela respectiva Unidade Universitária, essa entrevista é realizada pelos técnicos do NUSEL/PRODEP Núcleo de Seleção da PRODEP, apesar desses servidores não possuírem formação na área organizacional. Ficou estabelecido que esse procedimento ocorreria dessa forma, porque nesses casos não haveria necessidade de análise de perfil, pois esse novo servidor tendo ou não compatibilidade com a atividade a ser desenvolvida naquele ambiente seria para lá enviado. 
O instrumento utilizado nas entrevistas admissionais sofreu alteração há aproximadamente 5 anos. Atualmente essa etapa é realizada mediante dois roteiros, um para levantamento de dados pessoais, acadêmicos e profissionais, e o outro contendo 7 perguntas de caráter comportamental, a fim de reconhecer reações frente a algumas situações hipotéticas.

O que ocorre, entretanto, é que apesar de o segundo roteiro já estar melhor estruturado e ajudar a conhecer de forma razoável a reação dos técnicos frente a situações adversas, este instrumento é utilizado de maneira assistemática, pelos motivos expostos acima, além de necessitar de um estudo aprofundado para melhor identificar comportamentos e atitudes.

Para Vieira e Machado (2011) a entrevista por competência se propõe a pesquisar comportamentos passados com o objetivo de prever comportamentos futuros que poderão ser utilizados para melhor aproveitamento do indivíduo na realização das suas atividades. Gil (1989) apresenta parecer semelhante ao considerar que este é também um instrumento importante para análise de comportamento presente e passado, colaborando para a previsão de comportamento futuro em situações idênticas.

Ocorre que o cargo de TAE possui atribuições bastante genéricas, além de possuir como requisito para ingresso no cargo apenas o $2^{\circ}$ grau completo, conforme descrição de cargos, constante da Lei $\mathrm{n}^{\mathrm{o}}$ 11.091/2005, que trata do Plano de Carreira dos Cargos TécnicoAdministrativos em Educação. Como resultado, razoável número de servidores capacitados, com perfis genéricos, são aprovados, recaindo sobre a Pró-Reitoria de Desenvolvimento de Pessoas (PRODEP), o desafio de lotá-los em Unidades Universitárias ou Administrativas, que lhes garantam uma boa receptividade e integração, compatibilidade entre sua formação e as atividades a serem desenvolvidas.

No concurso público realizado em 2013, pela Universidade Federal da Bahia, ofereceu-se 50 vagas para o cargo de Assistente em Administração. Este concurso teve vigência de 1 ano, foi prorrogado por mais 1 ano e prescreveu em janeiro de 2016. Foram homologados aproximadamente 100 candidatos e todos foram nomeados.

Das 52 vagas oferecidas para esse cargo, inscreveram-se 26.155 candidatos, destes, 3.078 informaram possuir o $2^{\circ}$ grau completo; 2.136 com curso superior incompleto; 4.061 com graduação em qualquer área; 647 com especialização; 176 com mestrado e 2 com doutorado. Não informaram a escolaridade 15.753 candidatos.

Em relação aos candidatos classificados nas 52 vagas oferecidas, 6 informaram possuir o $2^{\circ}$ grau completo; 4 com curso superior incompleto; 24 com graduação em qualquer área; 2 
com especialização; 1 com mestrado. Não informaram a escolaridade 15 candidatos. Constata-se que dos candidatos inscritos $34,49 \%$ possuem formação acima da requerida para esse cargo e dos classificados nas vagas, $60 \%$.

O que se verifica é que o ocupante desse cargo, a depender da sua lotação, pode desempenhar atividades das mais elementares às mais complexas, que vai do simples controle de claviculário (quadro ou móvel onde se guardam as chaves) até a análise de complexos processos. Com base nas informações apresentadas nesta caracterização do processo adotado pela UFBA, com base em Aldaay (2000), Zarifian (2001), Brandão e Guimaraes (2001), Bergue (2010), Schikmann (2010), Brandão (2013), fica clara a urgência em se promover ações que aperfeiçoem os instrumentos utilizados na admissão de pessoas, a fim de reconhecer as competências necessárias ao bom atendimento das demandas organizacionais, permitindo assim, que a IFES alcance maior eficiência na prestação dos serviços públicos sob sua responsabilidade. As análises avançam a partir da apresentação, na subseção seguinte, dos resultados obtidos com o survey elaborado a partir de categorias complementares para o estudo do fenômeno.

\subsection{O PROCESSO DE ALOCAÇÃO DE PESSOAS: UMA POSSÍVEL ANÁLISE}

As análises dos dados coletados são discutidas por cada uma das categorias elencadas por Baptista (2011), conforme tabelas trazidas na sequência do artigo.

Tabela 1 Processo de lotação

\begin{tabular}{|c|c|c|c|c|c|}
\hline Indicadores & 1 & 2 & 3 & 4 & 5 \\
\hline $\begin{array}{l}\text { A entrevista admissional } \\
\text { realizada pela CDH/PRODEP } \\
\text { contribuiu para o meu processo } \\
\text { de lotação. }\end{array}$ & $\begin{array}{c}10 \\
(12,82 \%)\end{array}$ & $\begin{array}{c}10 \\
(12,82 \%)\end{array}$ & $\begin{array}{c}21 \\
(26,92 \%)\end{array}$ & $\begin{array}{c}18 \\
(23,08 \%)\end{array}$ & $\begin{array}{c}19 \\
(24,36 \%)\end{array}$ \\
\hline $\begin{array}{lr}\text { Minhas } & \text { competências } \\
\text { profissionais } & \text { foram } \\
\text { adequadamente identificadas na } \\
\text { entrevista admissional. }\end{array}$ & $\begin{array}{c}10 \\
(12,82 \%)\end{array}$ & $\begin{array}{c}14 \\
(17,95 \%)\end{array}$ & $\begin{array}{c}25 \\
(32,05 \%)\end{array}$ & $\begin{array}{c}16 \\
(20,51 \%)\end{array}$ & $\begin{array}{c}13 \\
(16,67 \%)\end{array}$ \\
\hline $\begin{array}{l}\text { Minhas competências pessoais } \\
\text { foram } \\
\text { identificadas adequadamente } \\
\text { admissional. }\end{array}$ & $\begin{array}{c}11 \\
(14,10 \%)\end{array}$ & $\begin{array}{c}13 \\
(16,67 \%)\end{array}$ & $\begin{array}{c}24 \\
(30,77 \%)\end{array}$ & $\begin{array}{c}19 \\
(24,36 \%)\end{array}$ & $\begin{array}{c}11 \\
(14,10 \%)\end{array}$ \\
\hline $\begin{array}{l}\text { A definição de minha unidade } \\
\text { de lotação levou em conta } \\
\text { minhas } \\
\text { profissionais. }\end{array}$ & $\begin{array}{c}16 \\
(20,51 \%)\end{array}$ & $\begin{array}{c}15 \\
(19,23 \%)\end{array}$ & $\begin{array}{c}18 \\
(23,08 \%)\end{array}$ & $\begin{array}{c}16 \\
(20,51 \%)\end{array}$ & $\begin{array}{c}13 \\
(16,67 \%)\end{array}$ \\
\hline $\begin{array}{l}\text { A definição de minha unidade } \\
\text { de lotação também levou em }\end{array}$ & $\begin{array}{c}14 \\
(17,95 \%)\end{array}$ & $\begin{array}{c}13 \\
(16,67 \%)\end{array}$ & $\begin{array}{c}23 \\
(29,49 \%)\end{array}$ & $\begin{array}{c}18 \\
(23,08 \%)\end{array}$ & $\begin{array}{c}10 \\
(12,82 \%) \\
\end{array}$ \\
\hline
\end{tabular}




\begin{tabular}{l|c|c|c|c|c}
\hline $\begin{array}{l}\text { conta minhas competências } \\
\text { pessoais. }\end{array}$ & & & & & \\
\hline $\begin{array}{l}\text { O documento contendo a } \\
\text { descrição das atividades do meu }\end{array}$ & & & & & \\
$\begin{array}{l}\text { cargo, entregue no momento da } \\
\text { entrevista admissional, está } \\
\text { compatível com as atividades } \\
\text { desempenhadas por mim. }\end{array}$ & $(10,82 \%)$ & $(7,69 \%)$ & $(21,79 \%)$ & $\mathbf{( 3 5 , 9 0 \% )}$ & $(21,79 \%)$ \\
\hline
\end{tabular}

Fonte: dados da pesquisa de campo, 2017.

Nessa primeira tabela, analisou-se a dimensão "Processo de lotação" verificando-se que a maioria dos respondentes tenderam a uma avaliação positiva, ou seja, acima de $60 \%$ dos servidores consultados, considerando-se as notas 3 a 5 da escala. Levando-se em conta todos os 6 indicadores, em termos numéricos, a nota 3 teve a maior média de respondentes, 21, enquanto a $n^{\circ} 1,12 ;$ a $n^{\circ} 2,12 ; n^{\circ} 4,19$ e a $n^{\circ} 5,14$. Entretanto, contrapondo-se ao preconizado por Brandão e Guimaraes (2001), Bergue (2010), Schikmann (2010), Brandão (2013), um número significativo de servidores, cerca de 40\%, não considerou que a definição de sua unidade de lotação levou em conta suas competências profissionais, apesar de um número aproximado, $38,46 \%$ afirmar que suas competências foram adequadamente identificadas, significando que, para alguns, a entrevista admissional está sendo realizada de forma efetiva, mas seus resultados não estão sendo utilizados adequadamente no processo de lotação.

A CDH/PRODEP, em consonância com o que pontua Bess (2016), realiza entrevista admissional com todos os novos servidores, independentemente de qual cargo eles ocupem, visando assim auxiliar na definição da lotação destes. Entretanto, como dito anteriormente, esse instrumento carece de aperfeiçoamento, para que possa aumentar as chances de sucesso na alocação dos novos servidores, além de procurar satisfazer ambos os lados envolvidos no processo: setores e servidores ingressantes. Em seguida, tem-se a análise dos da tabela 2.

Tabela 2 Relacionamento com a chefia imediata e colegas

\begin{tabular}{l|c|c|c|c|c}
\hline Indicadores & 1 & 2 & 3 & 4 & 5 \\
\hline $\begin{array}{l}\text { Minha visão em relação ao } \\
\text { desenvolvimento do trabalho é }\end{array}$ & $\begin{array}{c}4 \\
\text { semelhante à da minha chefia } \\
\text { imediata }\end{array}$ & $\begin{array}{c}10 \\
(5,13 \%)\end{array}$ & $\begin{array}{c}21 \\
(12,82 \%)\end{array}$ & $\begin{array}{c}\mathbf{2 6} \\
(26,92 \%)\end{array}$ & $\begin{array}{c}\mathbf{( 3 3 , 3 3 \% )} \\
(21,79 \%)\end{array}$ \\
\hline $\begin{array}{l}\text { Minha visão em relação ao } \\
\text { desenvolvimento do trabalho } \\
\text { geralmente é semelhante à dos } \\
\text { meus colegas de trabalho }\end{array}$ & $\begin{array}{c}3 \\
(3,85 \%)\end{array}$ & $\begin{array}{c}12 \\
(15,38 \%)\end{array}$ & $\begin{array}{c}23 \\
(29,49 \%)\end{array}$ & $\mathbf{2 4}$ & 16 \\
\hline
\end{tabular}




\begin{tabular}{|c|c|c|c|c|c|}
\hline $\begin{array}{l}\text { Minha chefia imediata é aberta } \\
\text { a opiniões diferentes acerca do } \\
\text { trabalho }\end{array}$ & $\begin{array}{c}4 \\
(5,13 \%)\end{array}$ & $\begin{array}{c}7 \\
(8,97 \%)\end{array}$ & $\begin{array}{c}8 \\
(10,26 \%)\end{array}$ & $\begin{array}{c}30 \\
(38,46 \%)\end{array}$ & $\begin{array}{c}29 \\
(37,18 \%)\end{array}$ \\
\hline $\begin{array}{l}\text { Tenho boa relação com meus } \\
\text { superiores }\end{array}$ & $\begin{array}{c}0 \\
(0 \%) \\
\end{array}$ & $\begin{array}{c}3 \\
(3,85 \%) \\
\end{array}$ & $\begin{array}{c}8 \\
(10,26 \%) \\
\end{array}$ & $\begin{array}{c}19 \\
(24,36 \%) \\
\end{array}$ & $\begin{array}{c}48 \\
(61,54 \%) \\
\end{array}$ \\
\hline $\begin{array}{l}\text { Tenho boa relação com meus } \\
\text { colegas de trabalho }\end{array}$ & $\begin{array}{c}0 \\
(0 \%)\end{array}$ & $\begin{array}{c}0 \\
(0,00 \%)\end{array}$ & $\begin{array}{c}3 \\
(3,85 \%)\end{array}$ & $\begin{array}{c}17 \\
(21,79 \%)\end{array}$ & $\begin{array}{c}58 \\
74,36 \%)\end{array}$ \\
\hline
\end{tabular}

Fonte: dados da pesquisa de campo, 2017.

Nesta categoria observa-se que há predominância da nota 4 da escala para os três primeiros indicadores e, para os aspectos relativos ao relacionamento com superiores e com colegas, prevalecendo a nota 5 . Entretanto, nos dois primeiros indicadores dessa tabela há um número significativo de respondentes, cuja visão em relação ao desenvolvimento do trabalho não é semelhante ao da chefia nem à dos colegas de trabalho, superando a casa dos $42 \%$, considerando-se a nota 3 da escala.

Outro achado importante nesta dimensão - minha chefia imediata é aberta a opiniões diferentes - é de que $75 \%$ admitiram ter liberdade de opinião junto à chefia; aproximadamente $25 \%$ dos respondentes tenderam a uma avaliação negativa, considerando as notas 1 a 3; e apenas 14\% avaliaram não ter liberdade para expor opiniões divergentes junto à chefia. Nesta categoria, analisando-se todos os 5 indicadores, prevaleceu a nota 5, com média de 34 respondentes, indicando que em termos gerais o relacionamento desses servidores com os colegas e com a chefia é bom, o que corrobora os achados do trabalho de Almeida e Meireles (2015) e Baptista (2011), no que se refere à dimensão "Sociabilidade". A seguir, trazem-se os dados e análises relativos à categoria "Desempenho de atividades".

Tabela 3 Desempenho de atividades

\begin{tabular}{|c|c|c|c|c|c|}
\hline Indicadores & 1 & 2 & 3 & 4 & 5 \\
\hline $\begin{array}{l}\text { As atividades desenvolvidas em } \\
\text { meu ambiente de trabalho são } \\
\text { compatíveis com às descritas no } \\
\text { edital do concurso }\end{array}$ & $\begin{array}{c}5 \\
(6,41 \%)\end{array}$ & $\begin{array}{c}5 \\
(6,41 \%)\end{array}$ & $\begin{array}{c}17 \\
(21,79 \%)\end{array}$ & $\begin{array}{c}26 \\
(33,33 \%)\end{array}$ & $\begin{array}{c}25 \\
(32,05 \%)\end{array}$ \\
\hline $\begin{array}{l}\text { Costumo utilizar meus } \\
\text { conhecimentos/experiências para } \\
\text { a realização das minhas } \\
\text { atividades profissionais }\end{array}$ & $\begin{array}{c}0 \\
(0,00 \%)\end{array}$ & $\begin{array}{c}4 \\
(5,13 \%)\end{array}$ & $\begin{array}{c}15 \\
(19,23 \%)\end{array}$ & $\begin{array}{c}22 \\
(28,21 \%)\end{array}$ & $\begin{array}{c}37 \\
(47,44 \%)\end{array}$ \\
\hline \begin{tabular}{lrr} 
Minhas & \multicolumn{2}{c}{ competências são } \\
suficientes para o & desempenho \\
de minhas & atividades \\
profissionais & \\
\end{tabular} & $\begin{array}{c}0 \\
(0,00 \%)\end{array}$ & $\begin{array}{c}7 \\
(8,97 \%)\end{array}$ & $\begin{array}{c}11 \\
(14,10 \%)\end{array}$ & $\begin{array}{c}26 \\
(33,33 \%)\end{array}$ & $\begin{array}{c}34 \\
(43,59 \%)\end{array}$ \\
\hline $\begin{array}{l}\text { Tenho dificuldade para } \\
\text { desenvolver minhas atividades } \\
\text { profissionais }\end{array}$ & $\begin{array}{c}44 \\
(56,41 \%)\end{array}$ & $\begin{array}{c}11 \\
(14,10 \%)\end{array}$ & $\begin{array}{c}8 \\
(10,26 \%)\end{array}$ & $\begin{array}{c}12 \\
(15,38 \%)\end{array}$ & $\begin{array}{c}3 \\
(3,85 \%)\end{array}$ \\
\hline
\end{tabular}




\begin{tabular}{l|c|c|c|c|c}
\hline $\begin{array}{l}\text { Seria melhor aproveitado se } \\
\text { estivesse lotado em outra } \\
\text { Unidade Universitária }\end{array}$ & $\begin{array}{c}\mathbf{2 5} \\
\mathbf{( 3 2 , 0 5 \% )}\end{array}$ & $\begin{array}{c}12 \\
(15,38 \%)\end{array}$ & $\begin{array}{c}16 \\
(20,51 \%)\end{array}$ & $\begin{array}{c}9 \\
(11,54 \%)\end{array}$ & $\begin{array}{c}16 \\
(20,51 \%)\end{array}$ \\
\hline $\begin{array}{l}\text { Meu potencial de trabalho é bem } \\
\text { aproveitado na realização de } \\
\text { minhas atividades profissionais }\end{array}$ & $\begin{array}{c}3 \\
(3,85 \%)\end{array}$ & $\begin{array}{c}16 \\
(20,51 \%)\end{array}$ & $\begin{array}{c}\mathbf{2 4} \\
\mathbf{( 3 0 , 7 7 \% )}\end{array}$ & $\begin{array}{c}16 \\
(20,51 \%)\end{array}$ & $\begin{array}{c}19 \\
(24,36 \%)\end{array}$ \\
\hline
\end{tabular}

Fonte: dados da pesquisa de campo, 2017.

$\mathrm{Na}$ análise desta categoria, os dados demonstram que os três primeiros indicadores foram bem avaliados, confirmando que grande parte dos servidores ocupantes desse cargo possuem qualificação para o desempenho das suas atividades, reforçando-se assim, os achados advindos das análises realizadas por Baptista (2011) e Almeida e Meireles (2015), no que se refere à dimensão "Execução do trabalho". Percebe-se também um equilíbrio em torno de $70 \%$, entre o $3^{\circ}$ e o $4^{\circ}$ indicadores, confirmando coerência entre as respostas.

Com relação ao indicador "melhor aproveitamento em outra Unidade", 32,05\% assinalaram a nota 1 da escala, informando que estão satisfeitos em suas Unidades de lotação. Por outro lado, levando-se em conta as notas 3 a 5 desse mesmo quesito, pode-se afirmar que, aproximadamente $50 \%$ desses servidores, não estão satisfeitos em suas unidades de lotação, e $15,38 \%$ que assinalaram a nota 2 , cogitam, ainda que de forma moderada, a possibilidade de serem melhor aproveitados em outros ambientes. Outro ponto observado é que em torno de $19,23 \%$ dos servidores afirmaram ter dificuldade para o desenvolvimento de suas atividades profissionais. Levando-se em conta todos os 6 indicadores, prevaleceu a nota $\mathrm{n}^{\mathrm{o}} 5$, com maior média de respondentes, 22, enquanto a $n^{\circ} 1,13$; a $n^{\circ} 2,9 ; n^{0} 3,15$ e a $n^{\circ} 4,19$. Os dados da tabela 4, referentes aos "processos de trabalho são dispostos a seguir.

Tabela 4 Processo de Trabalho

\begin{tabular}{l|c|c|c|c|c}
\hline Indicadores & 1 & 2 & 3 & 4 & 5 \\
\hline $\begin{array}{l}\text { Meu processo de trabalho é } \\
\text { bem estruturado }\end{array}$ & $\begin{array}{c}5 \\
(6,41 \%)\end{array}$ & $\begin{array}{c}17 \\
(21,79 \%)\end{array}$ & $\begin{array}{c}\mathbf{2 8} \\
\mathbf{( 3 5 , 9 0 \% )}\end{array}$ & $\begin{array}{c}22 \\
(28,21 \%)\end{array}$ & $\begin{array}{c}6 \\
(7,69 \%)\end{array}$ \\
\hline $\begin{array}{l}\text { Minha chefia imediata me } \\
\text { auxilia a compreender o meu } \\
\text { processo de trabalho }\end{array}$ & $\begin{array}{c}7 \\
(8,97 \%)\end{array}$ & $\begin{array}{c}12 \\
(15,38 \%)\end{array}$ & $\begin{array}{c}20 \\
(25,64 \%)\end{array}$ & $\begin{array}{c}\mathbf{2 1} \\
(\mathbf{2 6 , 9 2 \% )}\end{array}$ & $\begin{array}{c}18 \\
(23,08 \%)\end{array}$ \\
\hline $\begin{array}{l}\text { Meus colegas de trabalho me } \\
\text { auxiliam a compreender o meu } \\
\text { processo de trabalho }\end{array}$ & $\begin{array}{c}2 \\
(2,56 \%)\end{array}$ & $\begin{array}{c}10 \\
(12,82 \%)\end{array}$ & $\begin{array}{c}16 \\
(20,51 \%)\end{array}$ & $\begin{array}{c}\mathbf{2 9} \\
\mathbf{( 3 7 , 1 8 \% )}\end{array}$ & $\begin{array}{c}21 \\
(26,92 \%)\end{array}$ \\
\hline $\begin{array}{l}\text { Geralmente tenho sugestões de } \\
\text { mudança para o meu processo } \\
\text { de trabalho }\end{array}$ & $\begin{array}{c}7 \\
(8,97 \%)\end{array}$ & $\begin{array}{c}8 \\
(10,26 \%)\end{array}$ & $\begin{array}{c}22 \\
(28,21 \%)\end{array}$ & $\begin{array}{c}\mathbf{2 8} \\
\mathbf{( 3 5 , 9 0 \% )}\end{array}$ & $\begin{array}{c}13 \\
(16,67 \%)\end{array}$ \\
\hline $\begin{array}{l}\text { Sinto-me à vontade para } \\
\text { sugerir mudança no processo } \\
\text { de trabalho. }\end{array}$ & $\begin{array}{c}6 \\
(7,69 \%)\end{array}$ & $\begin{array}{c}4 \\
(5,13 \%)\end{array}$ & $\begin{array}{c}21 \\
(26,92 \%)\end{array}$ & $\begin{array}{c}23 \\
(29,49 \%)\end{array}$ & $\mathbf{( 3 0 , 7 7 \% )}$ \\
\hline
\end{tabular}

Fonte: dados da pesquisa de campo, 2017. 
$\mathrm{Na}$ categoria, o primeiro indicador teve uma avaliação de nota 3 da escala, indicando que o processo de trabalho pode ser melhor estruturado. Entre o segundo e o terceiro indicadores, verifica-se que há uma melhor relação, maior liberdade com os colegas do que com a chefia imediata. No quarto e quinto indicadores, a maioria das respostas concentrou-se nas notas 4 e 5, sugerindo uma boa participação dos respondentes nos processos de trabalho. Analisando-se essa categoria, percebe-se que a nota 4 teve a maior média de respondentes, 25; em $2^{\circ}$ lugar a nota 3 , com 21 ; em $3^{\circ}$, a nota 5 , com 16 . Pode-se inferir dessa análise que os processos de trabalho podem ser melhor estruturados. A seguir, são apresentados e analisados os dados contidos na tabela 5, acerca das necessidades de capacitação.

Tabela 5 Necessidades de Capacitação

\begin{tabular}{l|c|c|c|c|c}
\hline Indicadores & 1 & 2 & 3 & 4 & 5 \\
\hline $\begin{array}{l}\text { Costumo participar das ações } \\
\text { de capacitação oferecidas pela } \\
\text { Universidade }\end{array}$ & $\begin{array}{c}5 \\
(6,41 \%)\end{array}$ & $\begin{array}{c}9 \\
(11,54 \%)\end{array}$ & $\begin{array}{c}9 \\
(11,54 \%)\end{array}$ & $\begin{array}{c}24 \\
(30,77)\end{array}$ & $\begin{array}{c}\mathbf{3 1} \\
\mathbf{3 9 , 7 4 \% )}\end{array}$ \\
\hline $\begin{array}{l}\text { As ações de capacitação } \\
\text { contribuem para a realização } \\
\text { do meu trabalho }\end{array}$ & $\begin{array}{c}3 \\
(3,85 \%)\end{array}$ & $\begin{array}{c}8 \\
(10,26 \%)\end{array}$ & $\begin{array}{c}24 \\
(30,77 \%)\end{array}$ & $\begin{array}{c}\mathbf{2 7} \\
\mathbf{( 3 4 , 6 2 \% )}\end{array}$ & $\begin{array}{c}16 \\
(20,51 \%)\end{array}$ \\
\hline $\begin{array}{l}\text { As ações de capacitação } \\
\text { atendem às minhas aspirações } \\
\text { profissionais }\end{array}$ & $\begin{array}{c}7 \\
(8,97 \%)\end{array}$ & $\begin{array}{c}14 \\
(17,95 \%)\end{array}$ & $\begin{array}{c}\mathbf{2 8} \\
\mathbf{( 3 5 , 9 0 \% )}\end{array}$ & $\begin{array}{c}21 \\
(26,92 \%)\end{array}$ & $\begin{array}{c}8 \\
(10,26 \%)\end{array}$ \\
\hline $\begin{array}{l}\text { Minha chefia imediata } \\
\text { incentiva a minha participação } \\
\text { nas ações de capacitação }\end{array}$ & $\begin{array}{c}12 \\
(15,38 \%)\end{array}$ & $\begin{array}{c}8 \\
(10,26 \%)\end{array}$ & $\begin{array}{c}17 \\
(21,79 \%)\end{array}$ & $\begin{array}{c}19 \\
(24,36 \%)\end{array}$ & $\begin{array}{c}\mathbf{2 2} \\
\mathbf{( 2 8 , 2 1 \% )}\end{array}$ \\
\hline
\end{tabular}

Fonte: dados da pesquisa de campo, 2017.

Com relação a este quesito, observa-se que apenas $6,41 \%$ não costumam participar das ações de capacitação oferecidas. $11,54 \%$ participam muito pouco. $3,85 \%$ informaram que as ações de capacitação não contribuem para a realização do seu trabalho, ou contribuem muito pouco, somando-se as notas 1 e 2 dessa escala, aproximadamente $14 \%$.

Observa-se ainda que acima de $50 \%$ das chefias incentiva seus servidores a se capacitarem. Analisando-se os quatro indicadores dessa categoria, verifica-se que a nota 4 contou com a maior média de respondentes, 23; a nota 5, com 22; a nota 3, com 20, indicando que as ações de capacitação estão ocorrendo e cooperando com a realização das atividades. Sob tal perspectiva, considera-se adequado ao contexto da UFBA o que Pires et al (2008) afirmam em relação ao fato de que a evolução das competências no que se refere às dimensões pessoais e profissionais, se dá na medida em que ocorre o processo de aprendizagem, sendo para tal fundamental o cargo e as atividades realizadas, por guardarem 
estreita relação com a habilidade de cada funcionário para não somente resolver problemas, como também para se posicionar adequadamente frente a imprevistos e se disponibilizar a trocar conhecimentos tanto horizontal, quanto verticalmente no âmbito da estrutura hierárquica da qual faz parte. Entretanto, um número significativo atribuiu nota 3, significando que essas ações precisam passar por um processo de melhoria, ou que os respondentes, por alguma razão, não quiseram se posicionar mais criticamente a respeito do tema.

\section{CONSIDERAÇÕES FINAIS}

O presente trabalho buscou analisar as contribuições da entrevista admissional para o processo de alocação de pessoal, verificando a efetividade desse processo sob a ótica dos servidores TAE, identificando sua relação com o processo de lotação. Para isso, procedeu-se inicialmente àanálise documental e observação ativa, com o intuito de compreender e descrever como o processo admissional acontece na UFBA. Além disso, aplicou-se um questionário com os TAE que ingressaram em 2013, visando-se assim obter a percepão dos novos servidores acerca desse processo.

Dentre os principais achados, tem-se o resultado da análise da categoria "Processo de Lotação" sugerindo melhorias na concepção do instrumento de entrevista admissional realizada pela $\mathrm{CDH} / \mathrm{PRODEP}$, assim como a necessidade de se realizar o mapeamento de competências nas Unidades Universitárias da UFBA, sejam elas acadêmicas ou administrativas. Apesar da análise dos indicadores mostrar uma boa relação entre servidores e chefia imediata, não se pode esquecer que $25 \%$ dos respondentes tenderam a uma avaliação negativa no item: Minha chefia imediata é aberta a opiniões diferentes, levando-se em conta a nota 3 .

Constatou-se também que muitos respondentes não possuem dificuldade no desempenho de suas atividades, podendo ser este o motivo da insatisfação no ambiente de trabalho, verificada em $50 \%$ dos servidores que afirmaram que poderiam ser melhor aproveitados se estivessem lotados em outra unidade universitária, novamente considerando a nota 3. Obteve-se ainda que 18,23\% afirmaram ter dificuldade para desenvolver atividades profissionais, e 10,26\%, considerando a nota 3 , afirmaram relativa dificuldade. Tais resultados confirmaram os achados nos trabalhos de Almeida e Meireles (2014) e Baptista (2011), o que parece indicar a necessidade de melhorias em relação aos processos de trabalho da organização estudada. 
No que tange às "Necessidades de Capacitação", verifica-se que $17 \%$ dos servidores não costumam participar das ações de capacitação oferecidas. Dessa análise, alguns questionamentos podem ser feitos, a exemplo de: As ações de capacitação não atendem às necessidades dos novos servidores? Eles não necessitam de capacitação, visto que possuem formação acima da requerida? São indivíduos que entraram na UFBA, mas estão apenas à espera do próximo concurso para mudar de Instituição e, portanto, não estão interessados nessas ações? Tais questionamentos evidenciam a necessidade de novos estudos tomando-se por base os dados coletados nesse trabalho.

Entre as limitações dessa pesquisa está o escopo da população estudada, sugerindo novos estudos com envolvimento da alta gestão (pró-reitores, coordenadores/chefes de equipes de trabalho e dirigentes de unidades administrativas e acadêmicas). Finalmente, embora os dados do questionário aplicado não apontem situação crítica na UFBA, percebe-se que há espaço para a busca de resultados mais satisfatórios, no que diz respeito aos processos de alocação de pessoal, sugerindo-se o aprimoramento dos instrumentos utilizados no processo admissional com vistas a contribuir para esta organização e para processos de alocação de TAE que estejam em vigor em outras IFES.

\section{REFERÊNCIAS}

ABRÚCIO, Fernando Luiz. Trajetória recente da gestão pública brasileira: um balanço crítico e a renovação da agenda de reformas. RAP. Edição Especial Comemorativa. 67-86, 19672007. Disponível em: http://www.scielo.br/scielo.php?script=sci arttext\&pid=S0034$\underline{76122007000700005}$. Acesso em 07/07/2017.

ALDAY, H. E. C. O Planejamento estratégico dentro do conceito de administração estratégica. Rev. FAE. Curitiba, v.3, n.2, p. 9-16, maio/ago. 2000. Disponível em: https://revistafae.fae.edu/revistafae/article/view/505. Acesso em 09/06/2017.

ALMEIDA, Denise Ribeiro de. Trajetória institucional da universidade brasileira - a UFBA como reflexo e modelo. 2011, 284 f. Tese (Doutorado em Administração) Universidade Federal da Bahia, Salvador, 2011.

, Denise Ribeiro de. Mudança Estratégica nas Instituições Federais de Ensino Superior: o Caso UFBA. In: XXXVI Enanpad, Rio de Janeiro, Anais ..., Rio de Janeiro, ANPAD, 2012. CD ROM.

ALMEIDA, D. A.; MEIRELES, A. S. Satisfação e Trabalho: Uma análise do Grau de Satisfação dos Servidores em Estágio Probatório da UFBA. XV Colóquio Internacional de Gestão Universitária - CIGU. Anais... Desafios da Gestão Universitária no Século XXI. Mar del Plata. Argentina. 2015. Disponível em: 
https://repositorio.ufsc.br/xmlui/bitstream/handle/123456789/136146/102 00010.pdf?sequenc $\mathrm{e}=1$ \&isAllowed $=\mathrm{y}$. Acesso em: 03/04/2017

BAPTISTA, N.L. Subjetividade e trabalho: nível de satisfação dos novos servidores. Estudo de caso em uma autarquia pública federal. In: Congresso Nacional de Excelência em Gestão, 7, 2011. Niterói. Disponível em

http://www.excelenciaemgestao.org/Portals/2/documents/cneg7/anais/T11_0363_2172.pdf. Acesso em 09/06/2017.

BERGUE, S. T. Especialização em Gestão de Pessoas no Serviço Público: Uma perspectiva da vivência docente no contexto curso. In: Gestão de Pessoas: Bases Teóricas e

Experiências no Setor Público. Brasília, ENAP, 2010. Disponível em:

http://www.enap.gov.br/documents/586010/603556/Livro.pdf/b295469b-faec-42f2-954469b1984e17a8 . Acesso em: 10/06/2017.

BESS, Maiara Raiser Sühnel. Movimentação de servidores técnico-administrativos e gestão por competências em uma instituição federal de ensino superior: Uma proposta de suporte à decisão. Programa de Pós-Graduação (Mestrado) em Administração da Universidade Federal de Santa Catarina (PPGA/UFSC) Florianópolis, 2016. Disponível em: https://repositorio.ufsc.br/xmlui/bitstream/handle/123456789/173664/344116.pdf? sequence=1 \&isAllowed $=y$. Acesso em 09/06/2017.

BRANDÃO, H. P. Mapeamento de Competências. Métodos, Técnicas e Aplicações em Gestão de Pessoas. São Paulo, Atlas, 2013.

BRANDÃO, H. P.; GUIMARÃES, T. A. Gestão de Competências e Gestão de

Desempenho: tecnologias distintas ou instrumentos de um mesmo constructo? Revista de Administração de Empresas. S.P., v.41, n.1, p.8-15, jan/mar, 2001. http://www.scielo.br/pdf/rae/v41n1/v41n1a02.pdf . Acesso em 09/06/2017.

BRASIL. Decreto Presidencial no 5.707/2006. Disponível em http://www.planalto.gov.br/ccivil_03/_ato2004-2006/2006/decreto/d5707.htm . Acesso em 09/06/2017.

BRASIL. Emenda Constitucional $n^{0}$ 19, de 04 de junho de 1998. Disponível em: http://www.planalto.gov.br/ccivil_03/constituicao/emendas/emc/emc19.htm . Acesso em 09/06/2017.

BRASIL. Lei $\mathbf{n}^{\circ}$ 8.112, de 11 de dezembro de 1990. Dispõe sobre o regime jurídico dos servidores públicos civis da União, das autarquias e das fundações públicas federais. Disponível em: $<$ http:// www.planalto.gov.br/ccivil_03/leis/L8112cons.htm> . Acesso em: 07/05/2017.

BRASIL. Cadernos MARE da Reforma do Estado. c.16. Programa de Modernização do Poder Executivo Federal. Termo de Referência do Convênio de Cooperação Técnica com o BID. Brasília. DF. 1998. Disponível em:

http://www.bresserpereira.org.br/documents/mare/cadernosmare/caderno16.pdf .

Acesso em : 02/08/2017

BRESSER- PEREIRA, Luiz C.. Da Administração Pública Burocrática à Gerencial. Brasília, Revista do Serviço Público, 47(1) janeiro-abril,1996. Disponível em: 
http://www.bresserpereira.org.br/papers/1996/95.admpublicaburocraticaagerencial.pdf . Acesso em: 07/05/2017.

DOMINGUES, J. M. Instituições formais, cidadania e solidariedade complexa. Lua Nova, São Paulo, 66: 9-22, 2006. Disponível em: http://www.scielo.br/pdf/ln/n66/29082.pdf . Acesso em: 07/05/2017.

GIL, Antônio Carlos. Métodos e Técnicas de Pesquisa Social. SP. Ed. Atlas. 2a Edição.1989

PIRES A. K. et al. Gestão por Competências em Organizações de Governo. Mesa Redonda de Pesquisa-Ação. Brasília. Enap. 2007. Disponível em: http://repositorio.enap.gov.br/handle/1/383 . Acesso em: 07/05/2017.

SCHIKMANN, Rosane. Gestão Estratégica de Pessoas: Bases para a Concepção do Curso de Especialização em Gestão de Pessoas no Serviço Público. In: Gestão de Pessoas: Bases Teóricas e Experiências no Setor Público. ENAP, 2010. Disponível em: http://www.enap.gov.br/documents/586010/603556/Livro.pdf/b295469b-faec-42f2-954469b1984e17a8 . Acesso em: 10/06/2017.

TEIXEIRA FILHO, A. R.; ALMEIDA, D. R. Gestão por Competências: Mapeamento de Competências na Universidade Federal da Bahia. XIV Colóquio Internacional de Gestão Universitária - CIGU, Anais... A Gestão do Conhecimento e os Novos Modelos de Universidade. Florianópolis, 2014. Disponível em:

https://repositorio.ufsc.br/handle/123456789/131380 . Acesso em: 10/06/2017.

VERGARA, Sylvia Constant. Métodos de coleta de dados em campo. SP. Ed. Atlas. 2009

VIEIRA, Fernando de Oliveira; MACHADO, Dyuliana Maria Garcia Soares. A abordagem da gestão por competência para alocação de pessoal em organizações públicas. Anais... VII Congresso Nacional de Excelência em Gestão. 2011. Disponível em:

http://www.inovarse.org/sites/default/files/T11_0328_1754.pdf. Acesso em: : 07/05/2017.

ZARIFIAN, Philippe. Objetivo Competência. Por uma nova lógica. Tradução: Maria Helena C. V. Trelinsky. São Paulo, Atlas. 2001. 